\title{
Unsymmetric Dumbbell-Shaped Polyhedral Oligomeric Silsesquioxane (POSS) Compound as a Single Component POSS Hybrid
}

\author{
Mayu Nagao ${ }^{1}$, Taihei Hayashi ${ }^{1}$, Hiroaki Imoto ${ }^{1}$, Kensuke, Naka ${ }^{1,2 *}$ \\ 1 Faculty of Molecular Chemistry and Engineering, Graduate School of Science and \\ Technology, Kyoto Institute of Technology, Goshokaido-cho, Matsugasaki, Sakyo-ku, Kyoto \\ 606-8585, Japan \\ ${ }^{2}$ Materials Innovation Lab, Kyoto Institute of Technology, Goshokaido-cho, Matsugasaki, \\ Sakyo-ku, Kyoto 606-8585, Japan.
}


(a)

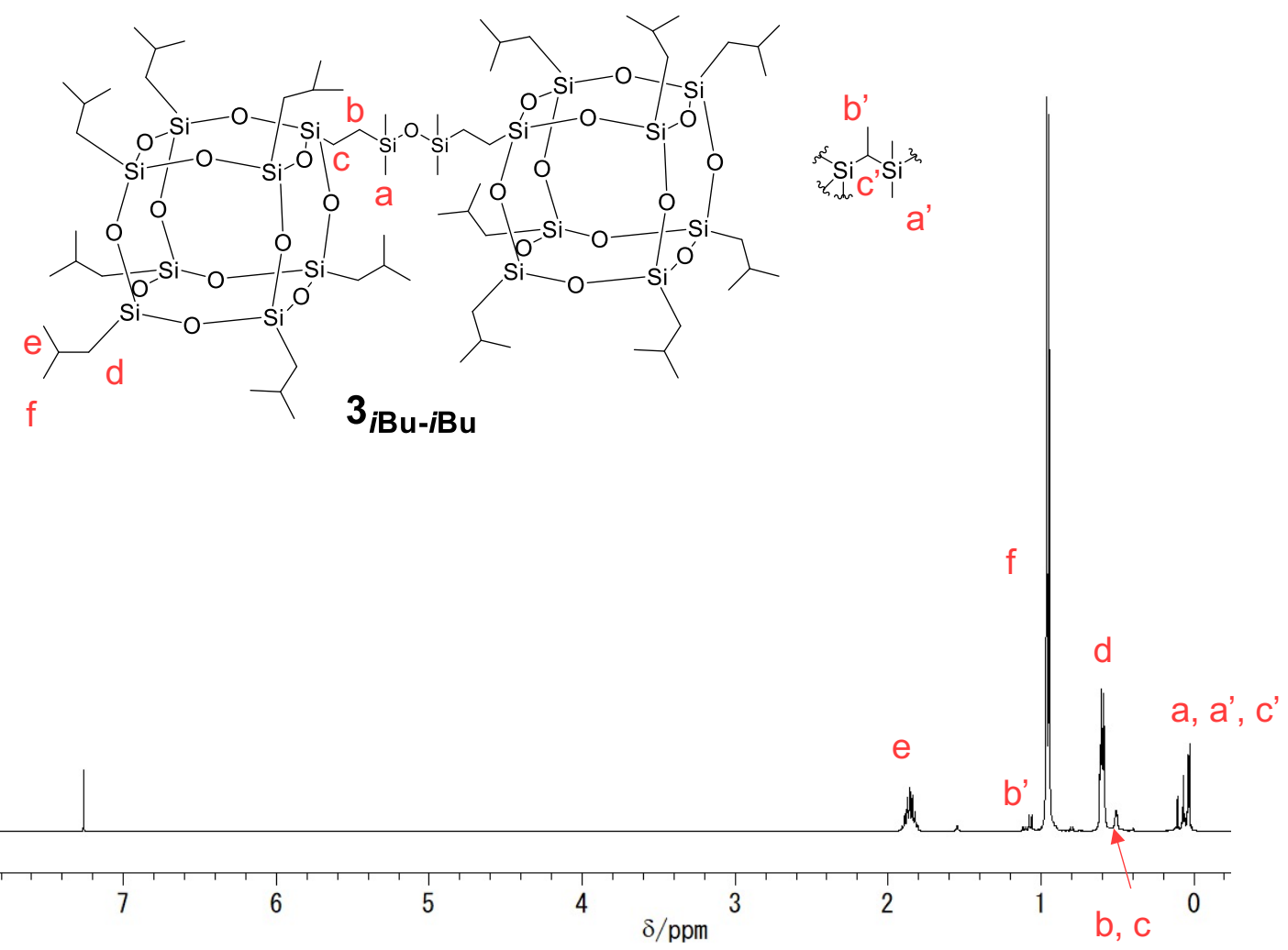

(b)

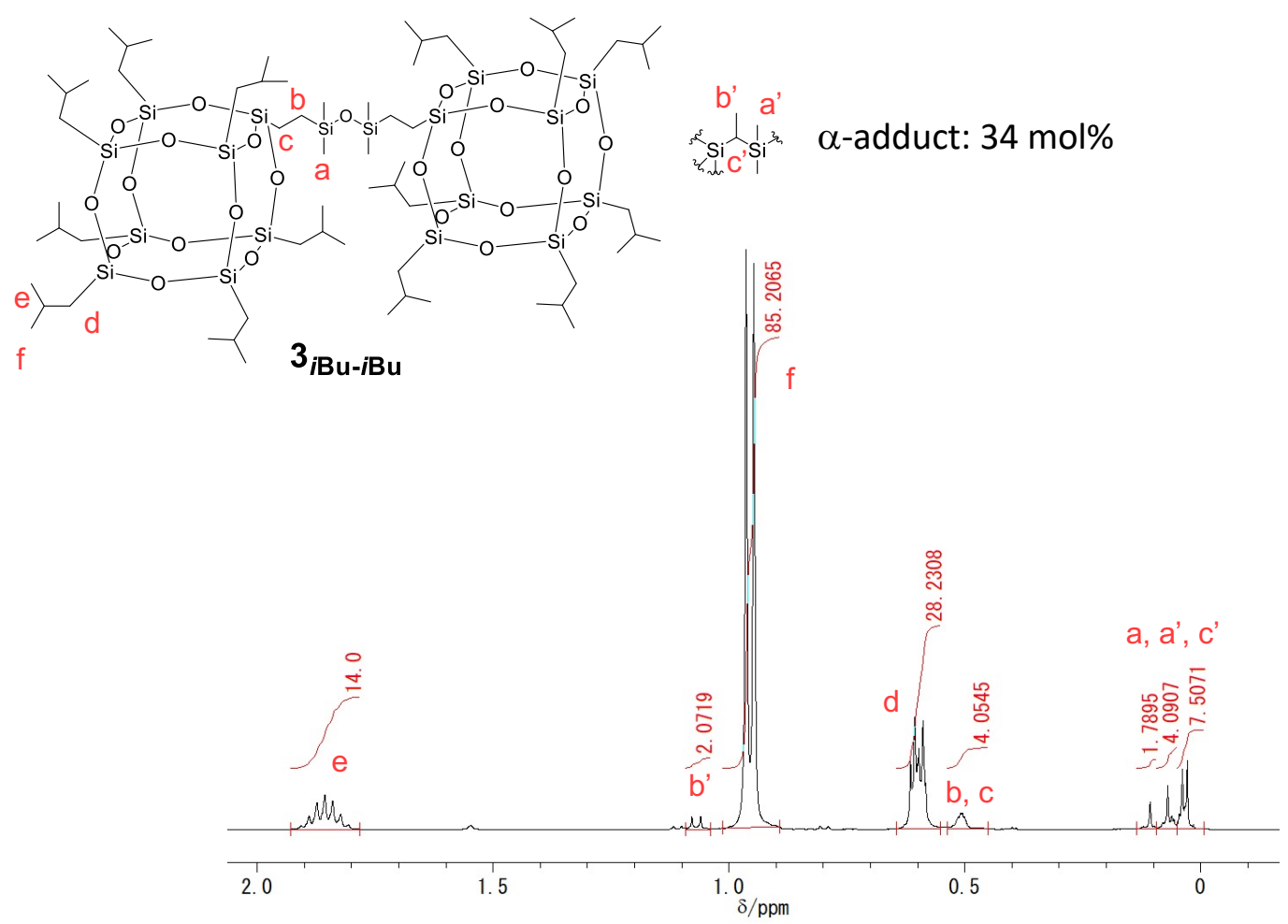

Figure S1 (a) ${ }^{1} \mathrm{H}-\mathrm{NMR}(400 \mathrm{MHz})$ and (b) expanded spectra of $\mathbf{3}_{\mathrm{iBu}-\mathrm{iBu}}$ in $\mathrm{CDCl}_{3}$. 


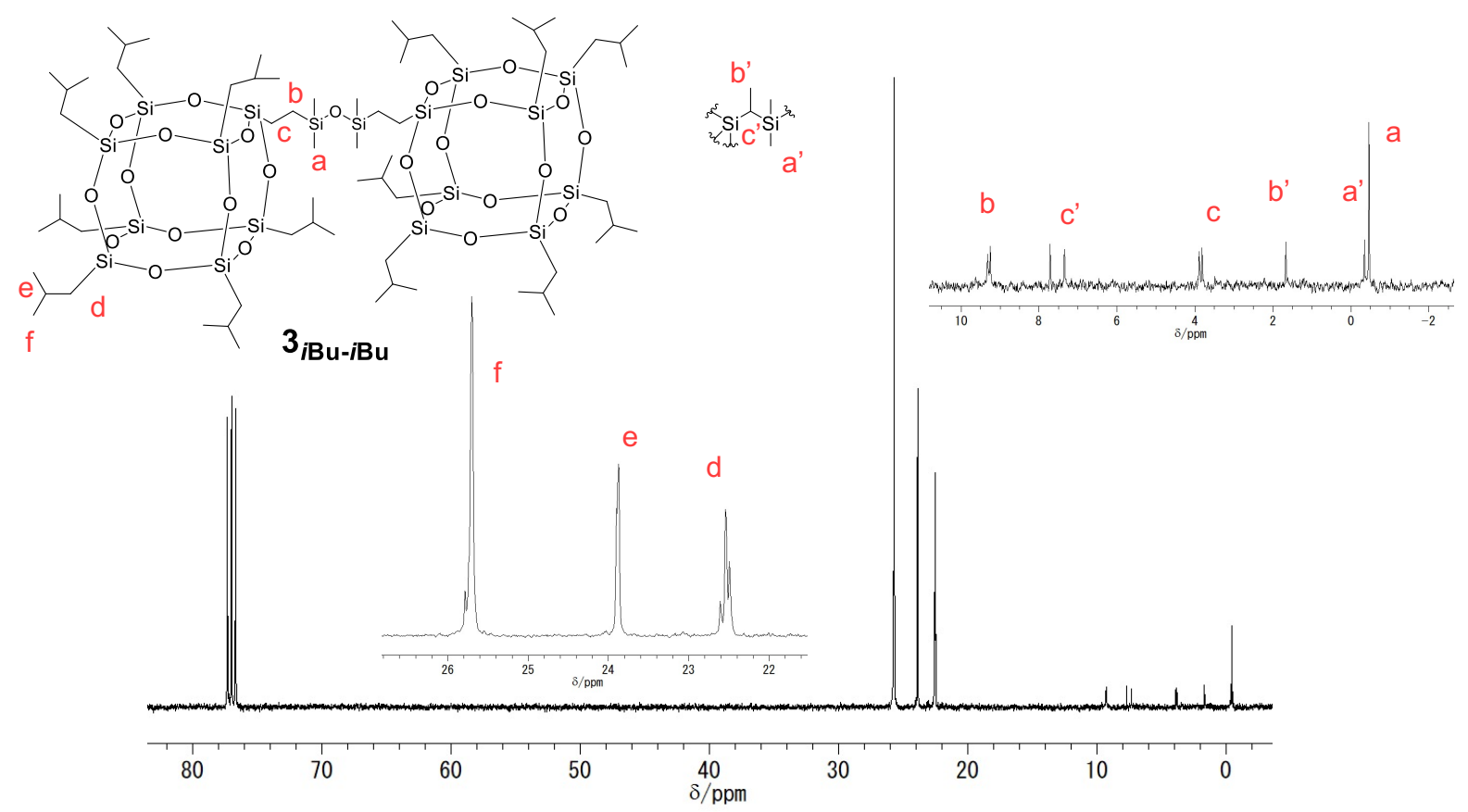

Figure S2 ${ }^{13} \mathrm{C}-\mathrm{NMR}(100 \mathrm{MHz})$ spectrum of $\mathbf{3}_{\mathrm{iBu}-\mathrm{iBu}}$ in $\mathrm{CDCl}_{3}$.
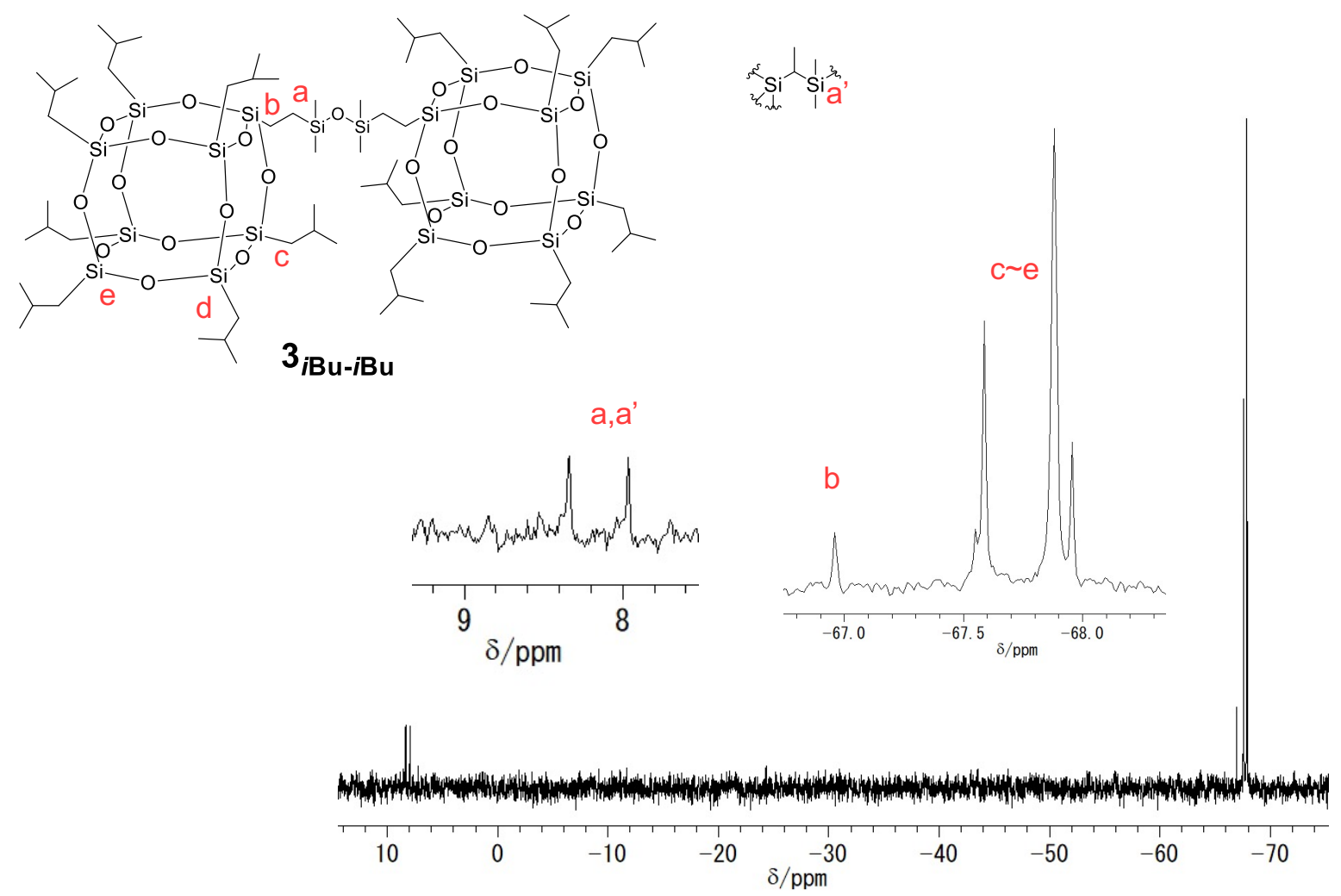

Figure $\mathbf{S 3}{ }^{29} \mathrm{Si}-\mathrm{NMR}(100 \mathrm{MHz})$ spectrum of $\mathbf{3}_{\mathbf{i B u}-\mathbf{i B u}}$ in $\mathrm{CDCl}_{3}$. 

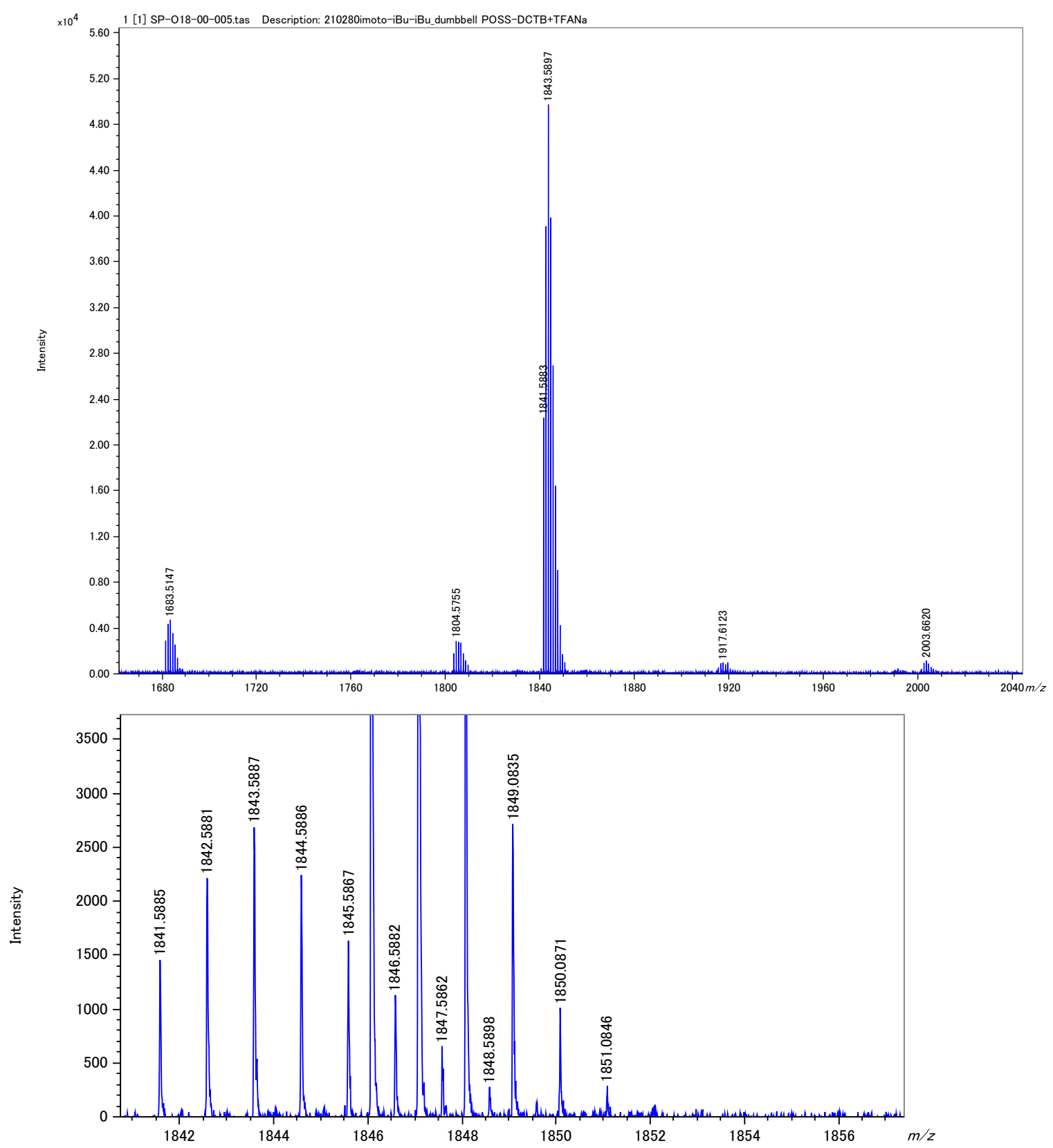

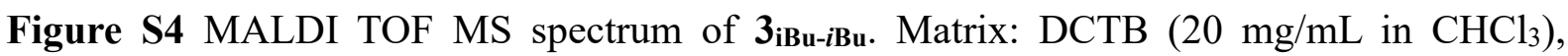
cationizing agents: sodium trifluoroacetate $(1 \mathrm{mg} / \mathrm{mL}$ in THF). (a) Full spectrum and (b) expanded view. 
(a)

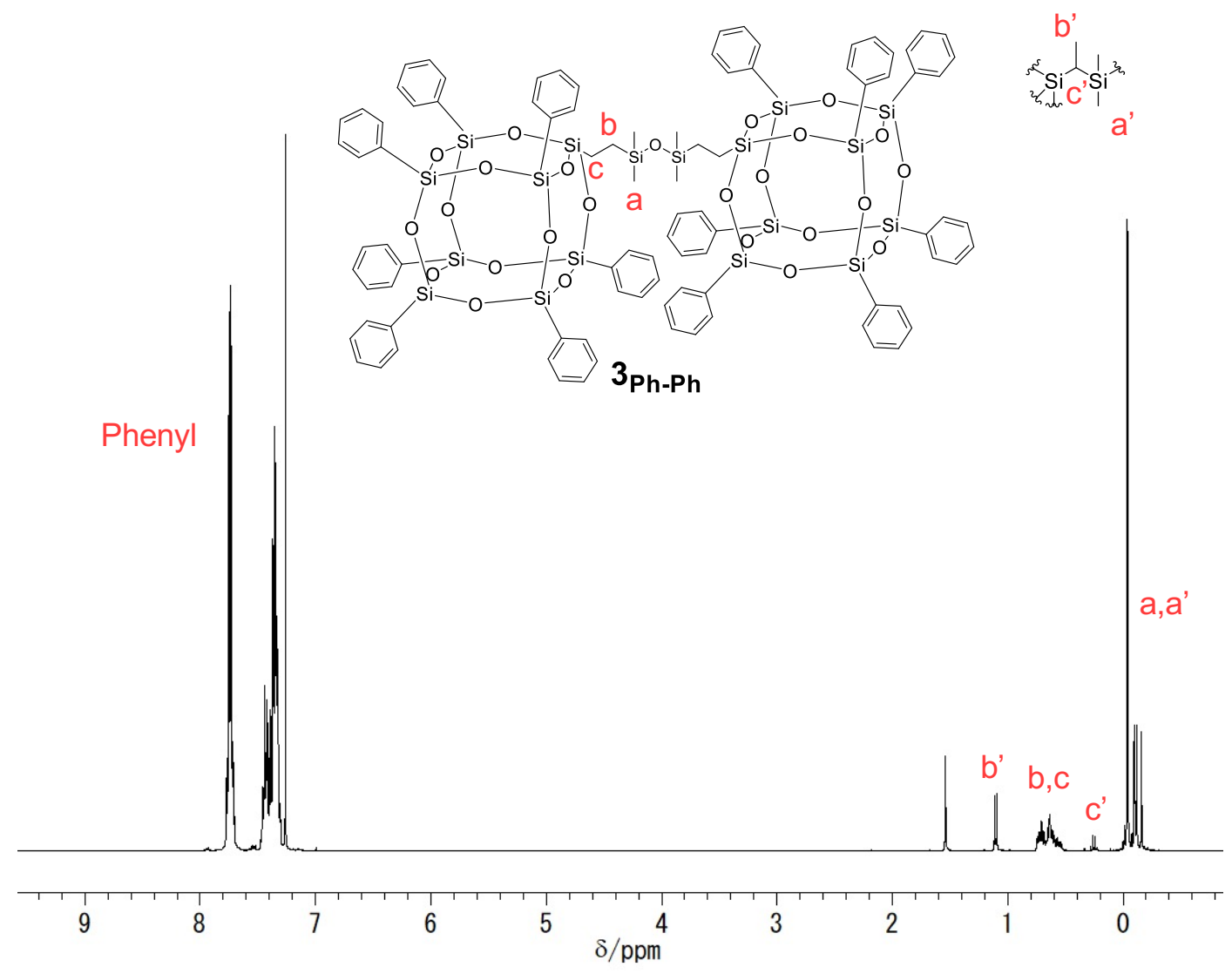

(b)

$\alpha$-adduct: 22 mol\%

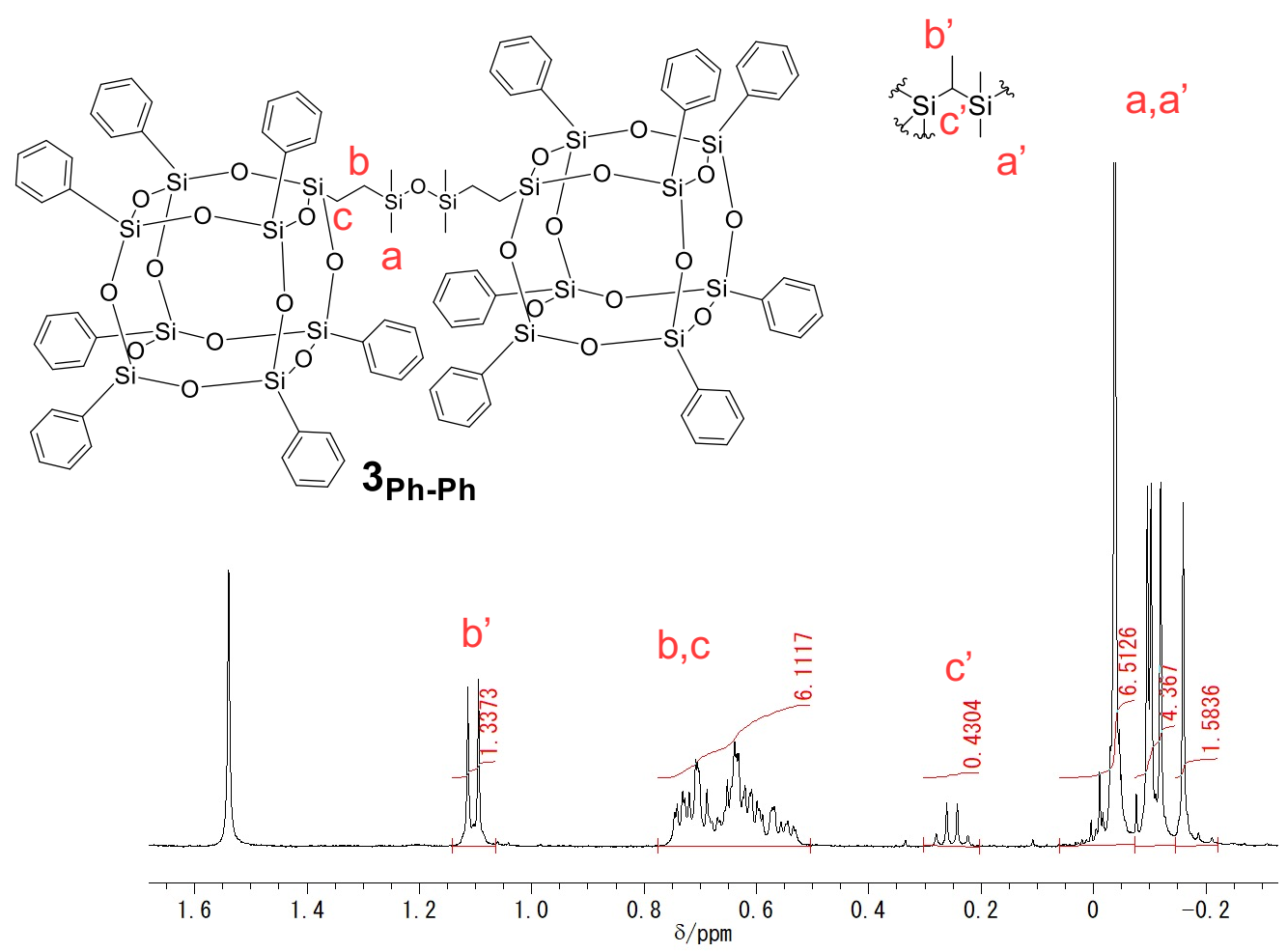

Figure S5 (a) ${ }^{1} \mathrm{H}-\mathrm{NMR}(400 \mathrm{MHz})$ and (b) expanded spectra of $\mathbf{3}_{\mathbf{P h}-\mathbf{P h}}$ in $\mathrm{CDCl}_{3}$. 


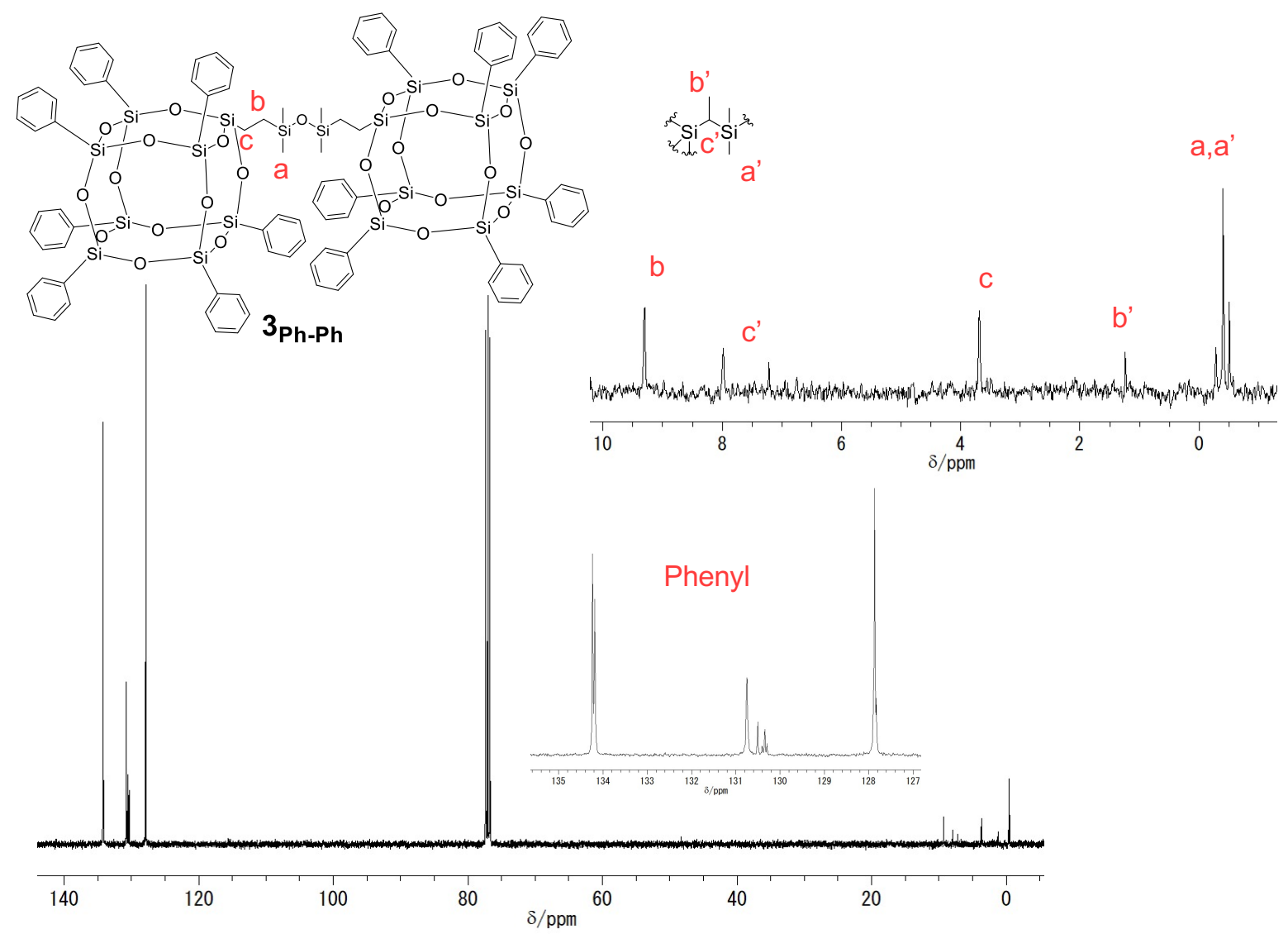

Figure S6 ${ }^{13} \mathrm{C}-\mathrm{NMR}(100 \mathrm{MHz})$ spectrum of $\mathbf{3}_{\mathbf{P h}-\mathbf{P h}}$ in $\mathrm{CDCl}_{3}$.

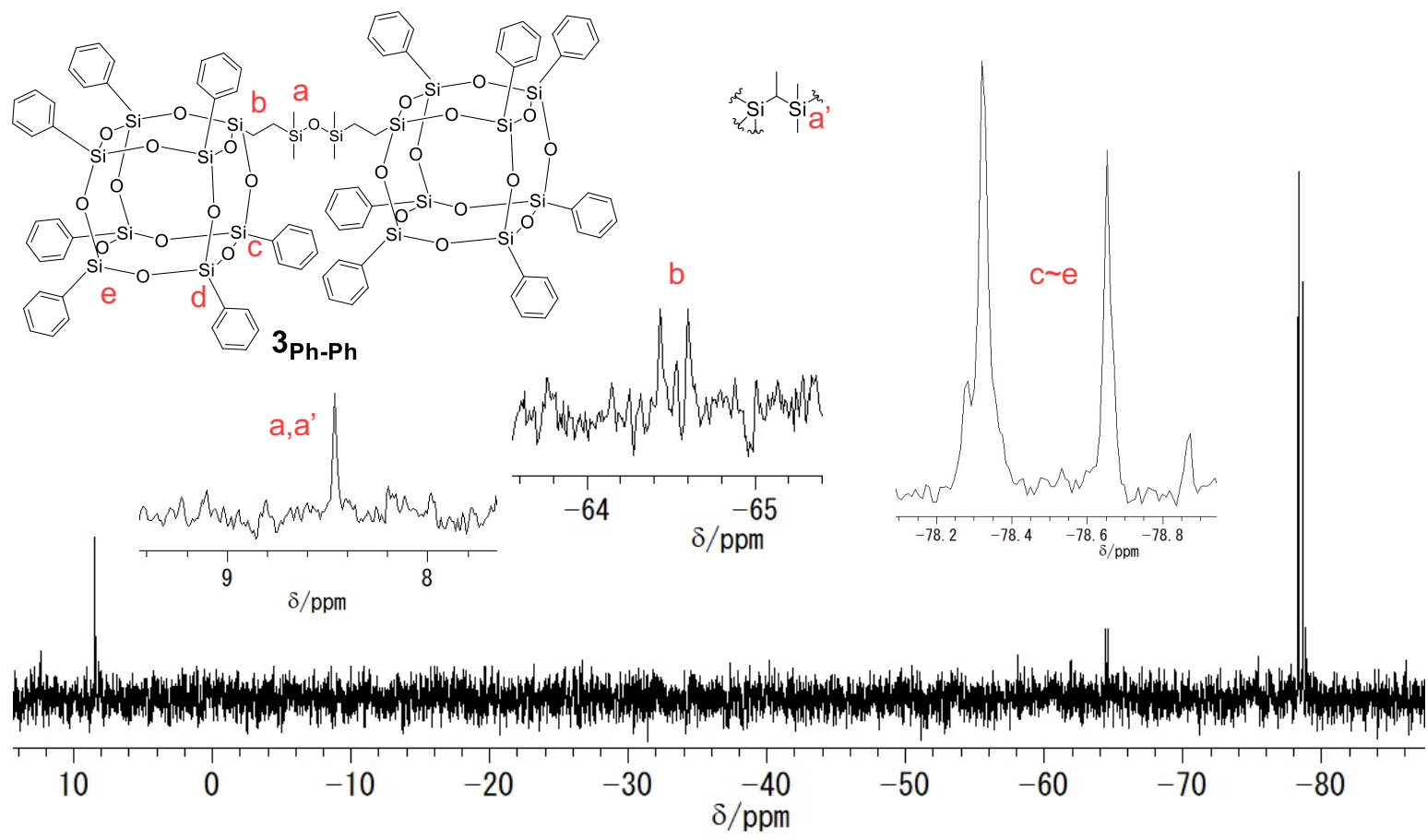

Figure $\mathbf{S} 7{ }^{29} \mathrm{Si}-\mathrm{NMR}(80 \mathrm{MHz})$ spectrum of $\mathbf{3}_{\mathbf{P h}-\mathbf{P h}}$ in $\mathrm{CDCl}_{3}$. 

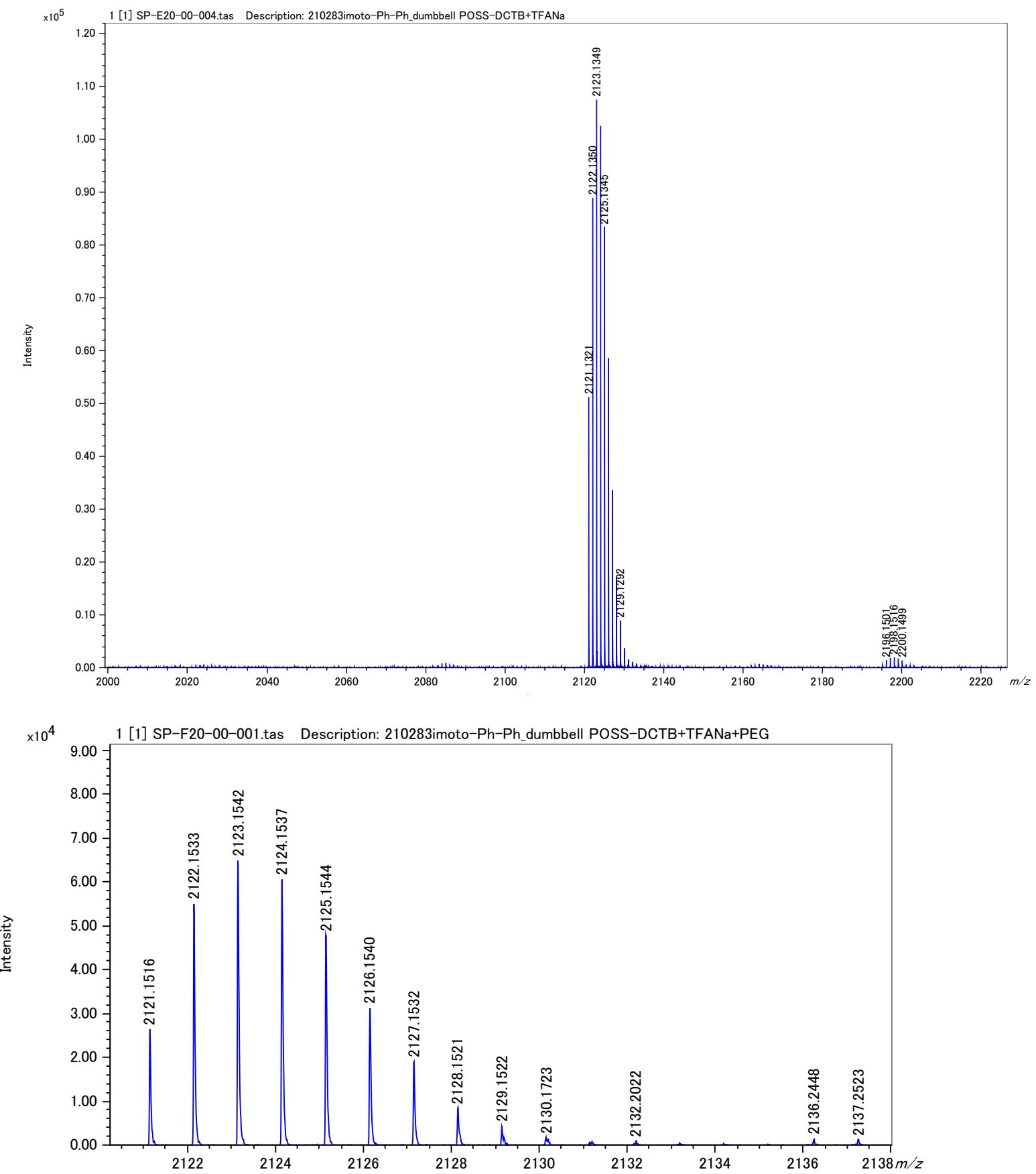

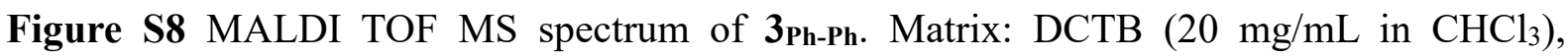
cationizing agents: sodium trifluoroacetate $(1 \mathrm{mg} / \mathrm{mL}$ in THF). (a) Full spectrum and (b) expanded view. 
(a)

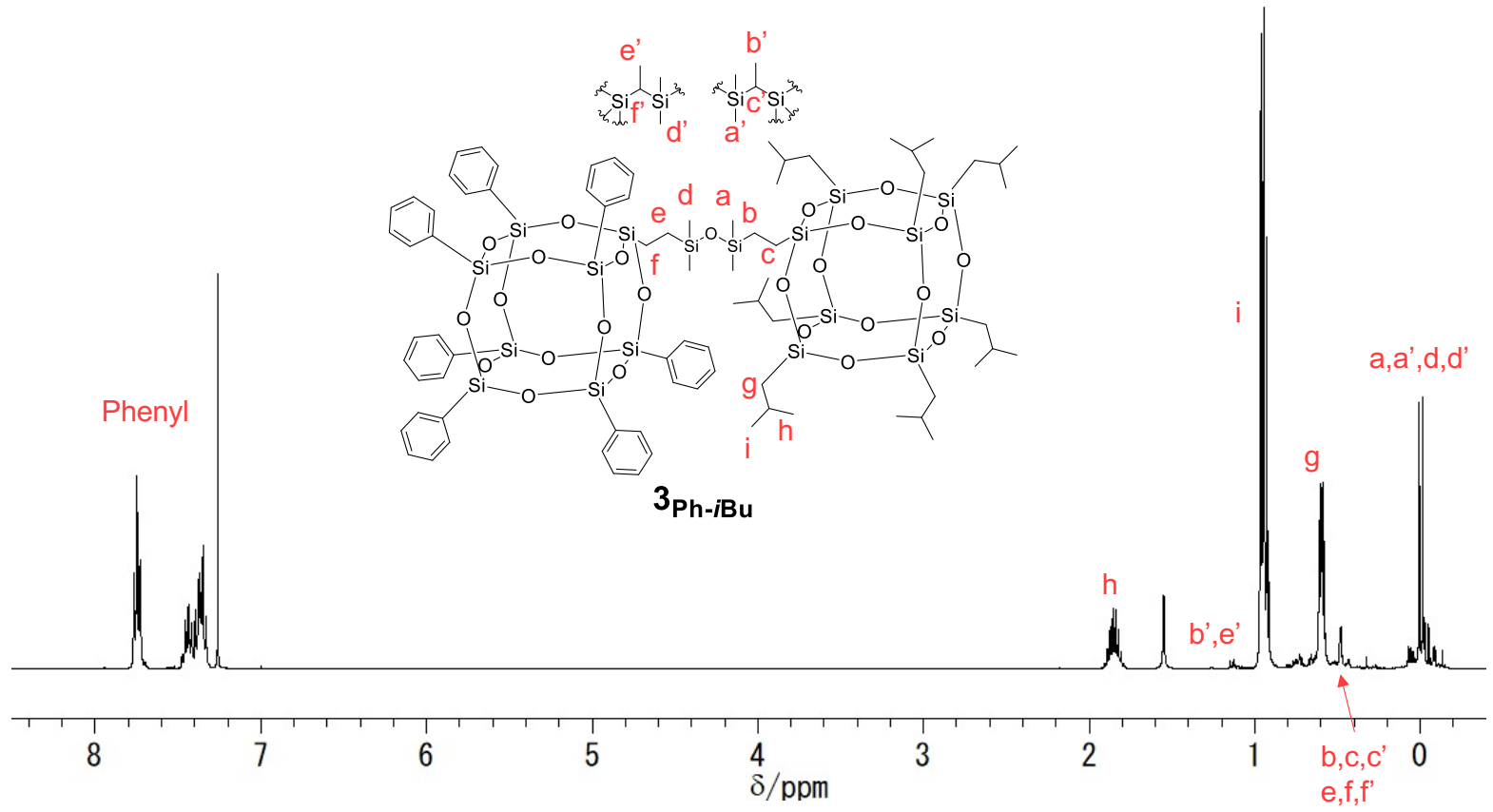

(b)

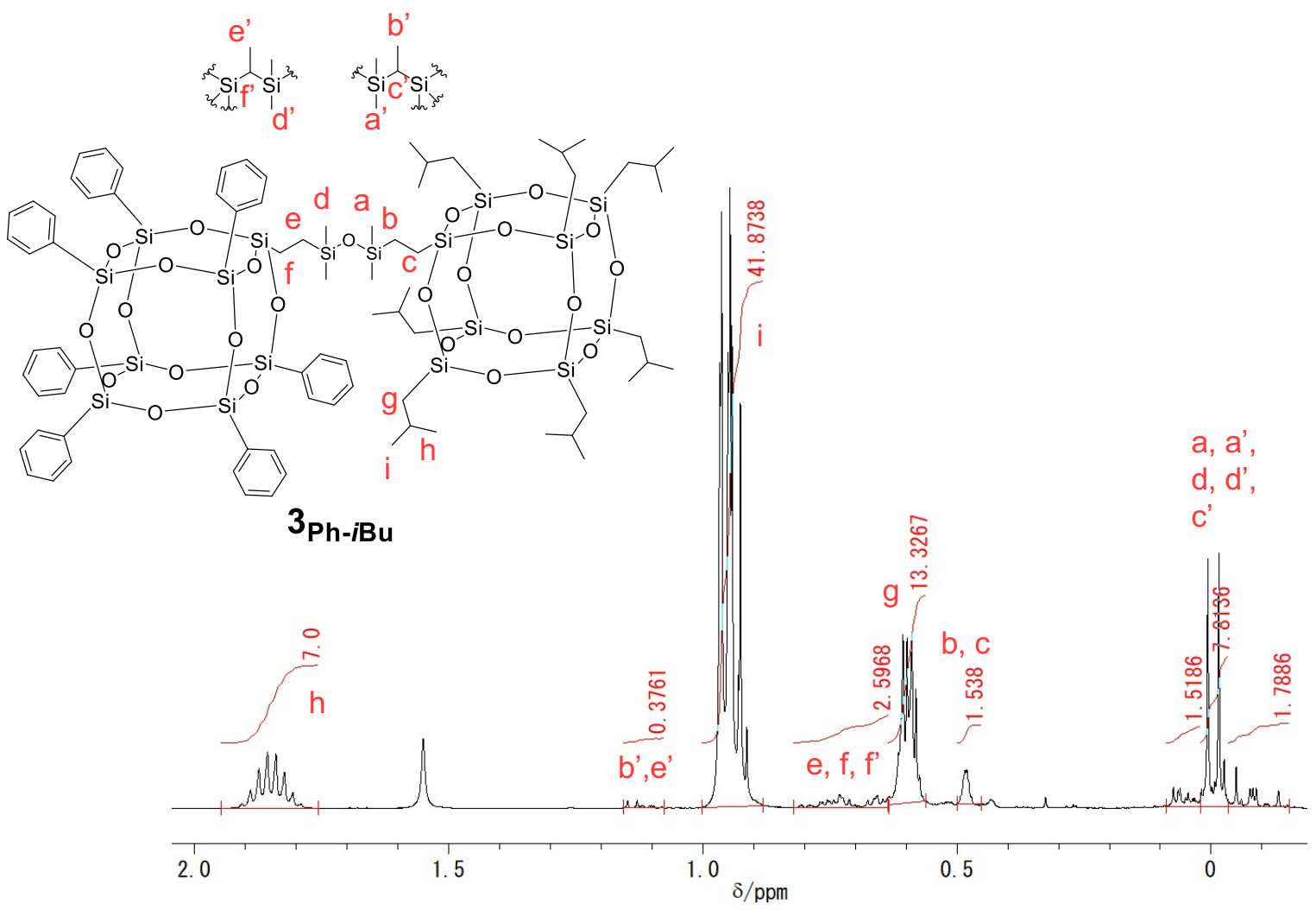

Figure S9 (a) ${ }^{1} \mathrm{H}-\mathrm{NMR}(400 \mathrm{MHz})$ and (b) expanded spectra of $\mathbf{3}_{\mathbf{P h}-\mathbf{B B u}}$ in $\mathrm{CDCl}_{3}$. 


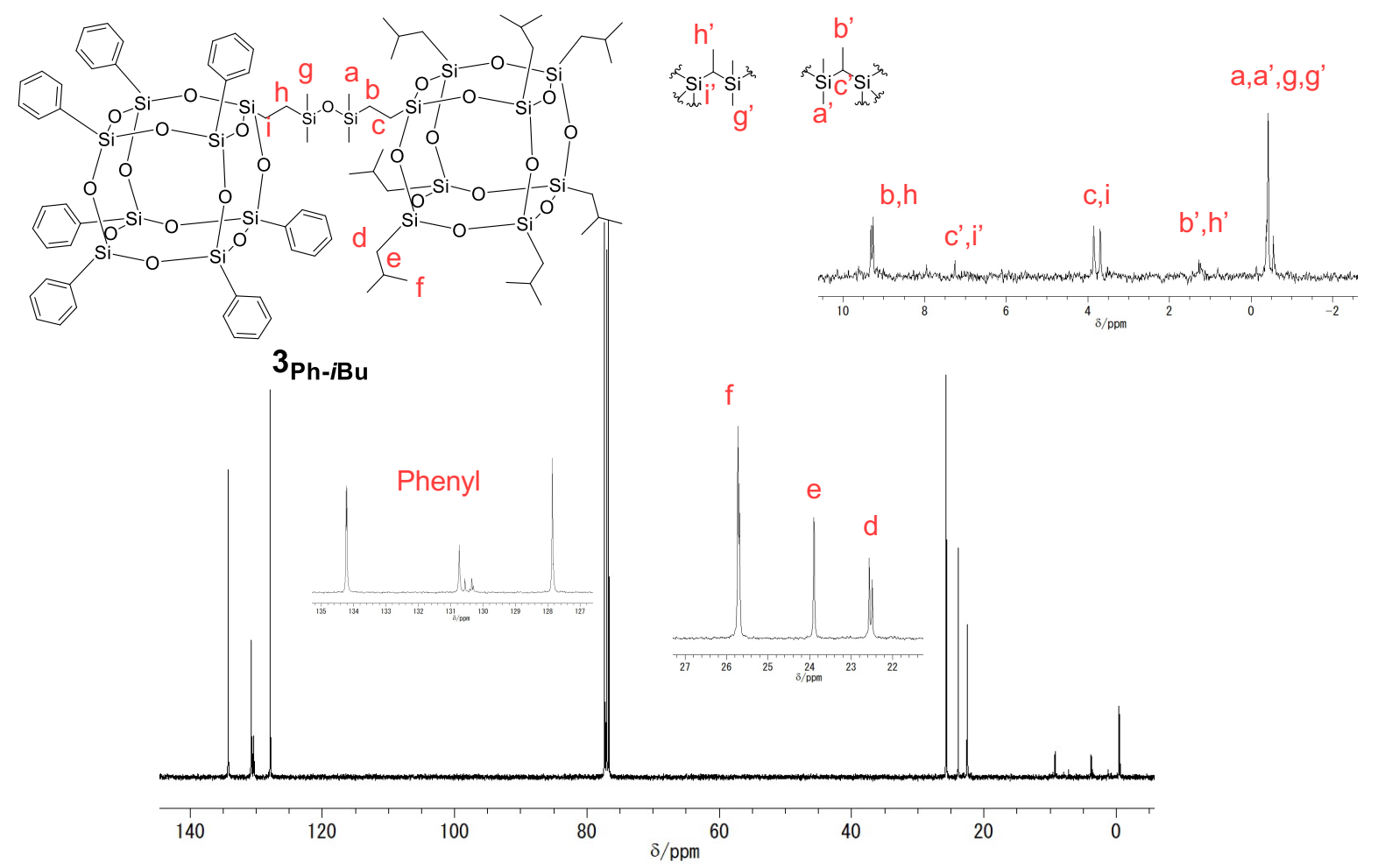

Figure S10 ${ }^{13} \mathrm{C}-\mathrm{NMR}(100 \mathrm{MHz})$ spectrum of $\mathbf{3}_{\mathbf{P h}-\mathbf{i B u}}$ in $\mathrm{CDCl}_{3}$.

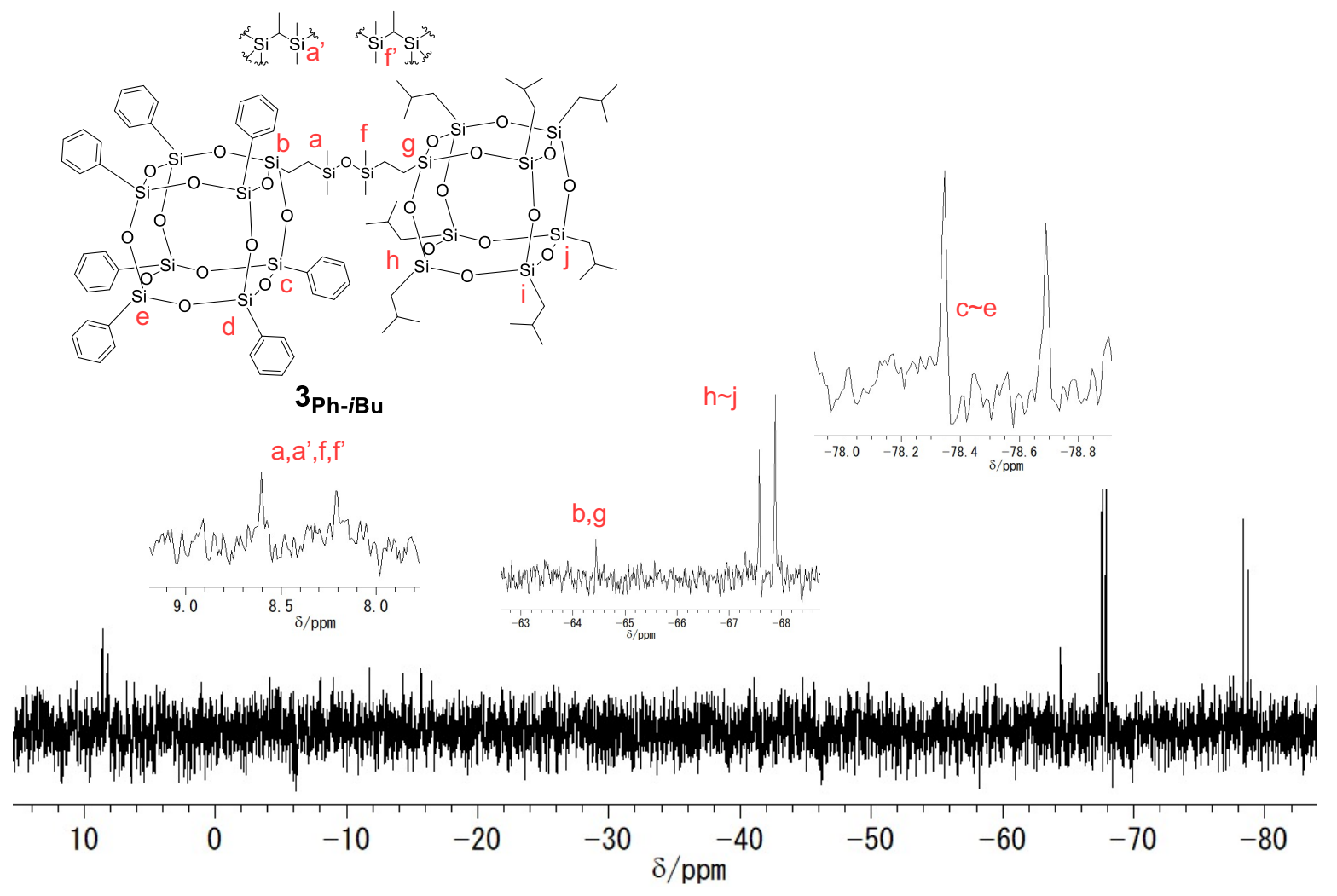

Figure $\mathbf{S 1 1}{ }^{29} \mathrm{Si}-\mathrm{NMR}(80 \mathrm{MHz})$ of $\mathbf{3}_{\mathbf{P h} \text {-iBu }}$ in $\mathrm{CDCl}_{3}$. 


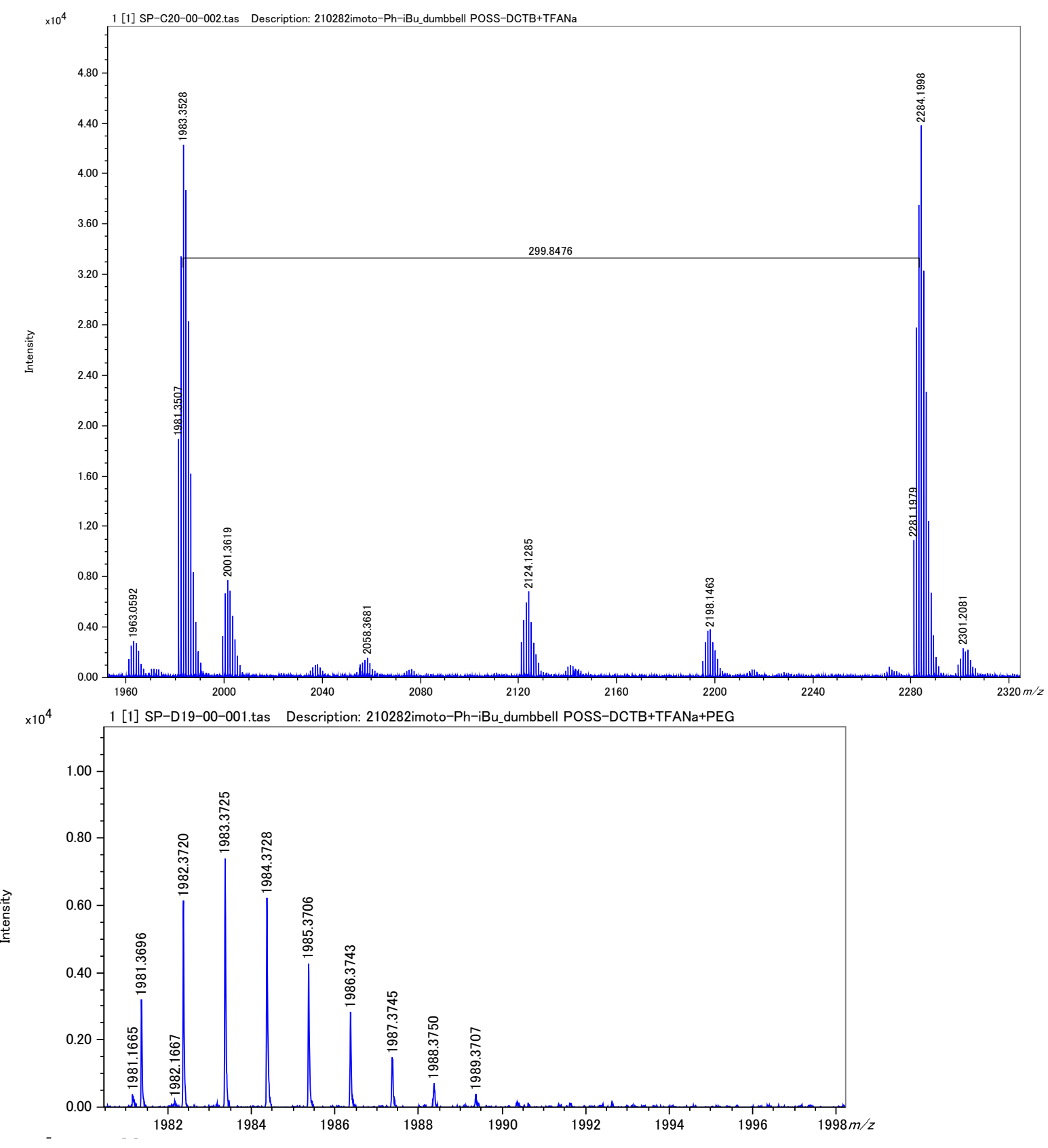

Figure S12 MALDI TOF MS spectrum of $\mathbf{3}_{\mathbf{P h}-\mathbf{B} \mathbf{B u}}$. Matrix: DCTB $\left(20 \mathrm{mg} / \mathrm{mL}\right.$ in $\mathrm{CHCl}_{3}$ ), cationizing agents: sodium trifluoroacetate $(1 \mathrm{mg} / \mathrm{mL}$ in THF). (a) Full spectrum and (b) expanded view.

Plausible explanation of observation the large peak at $2281.1979 \mathrm{~m} / \mathrm{z}$ is capture several phenyl radicals on the labile isobutyl moieties in the molecules during the MALDI-TOF-MS. 

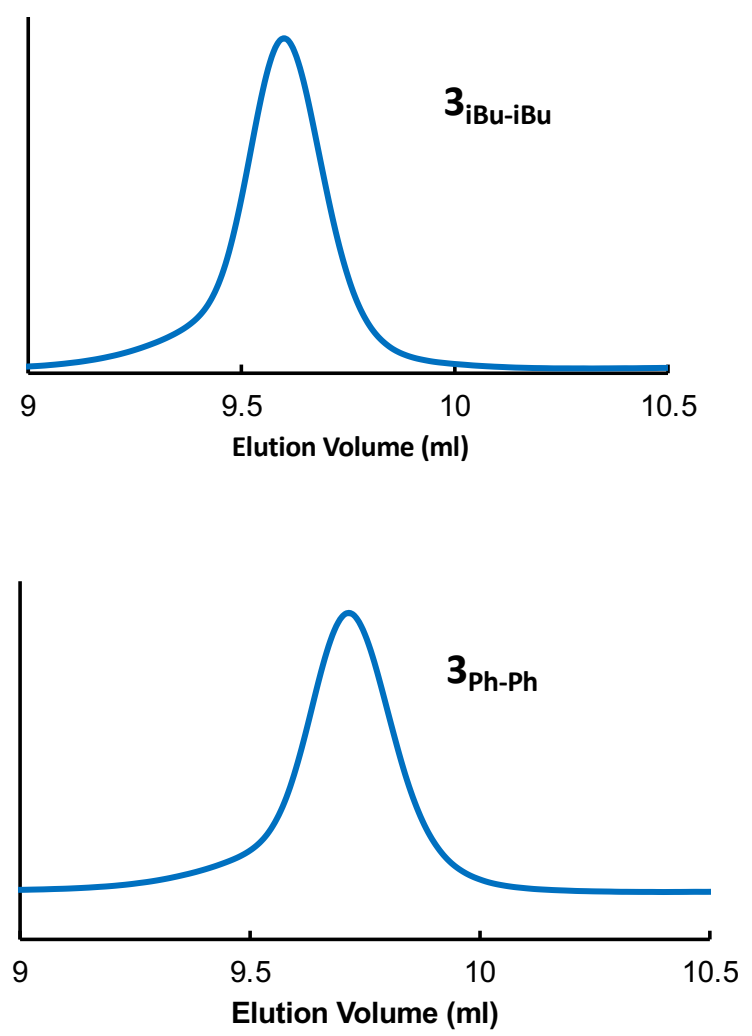
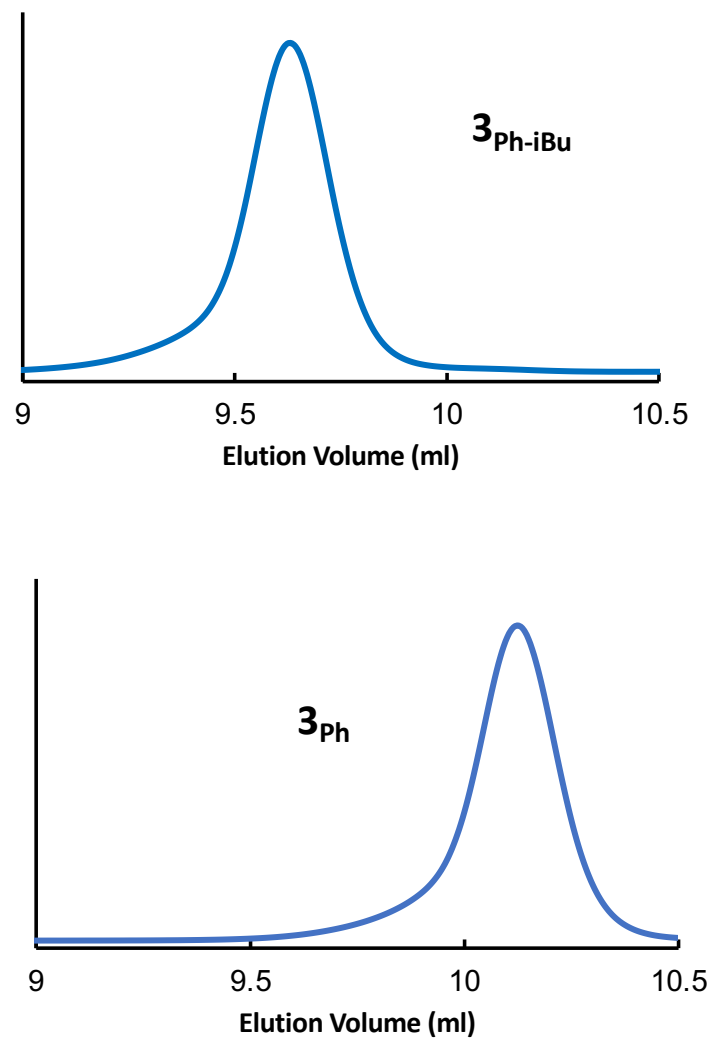

Figure S13 SEC traces of $\mathbf{3}_{\mathbf{i B u}-\mathbf{i B u}}, \mathbf{3}_{\mathbf{P h}-\mathbf{P h}}, \mathbf{3}_{\mathbf{P h}-\mathbf{i B u}}$, and $\mathbf{2}_{\mathbf{P h}}$ measured by Shodex KF-805L column using THF as an eluent with RI detection. 
(a)

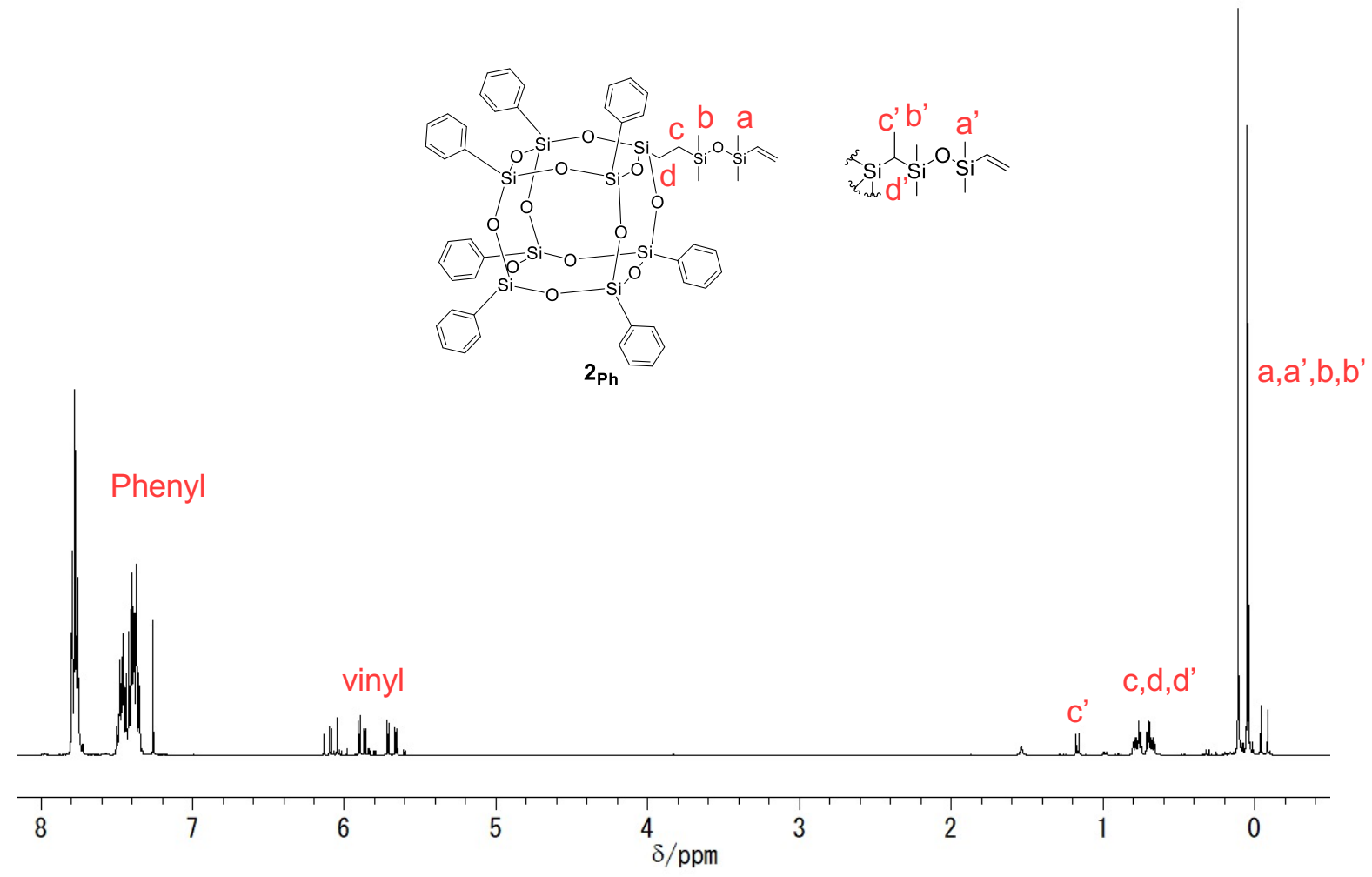

(b)

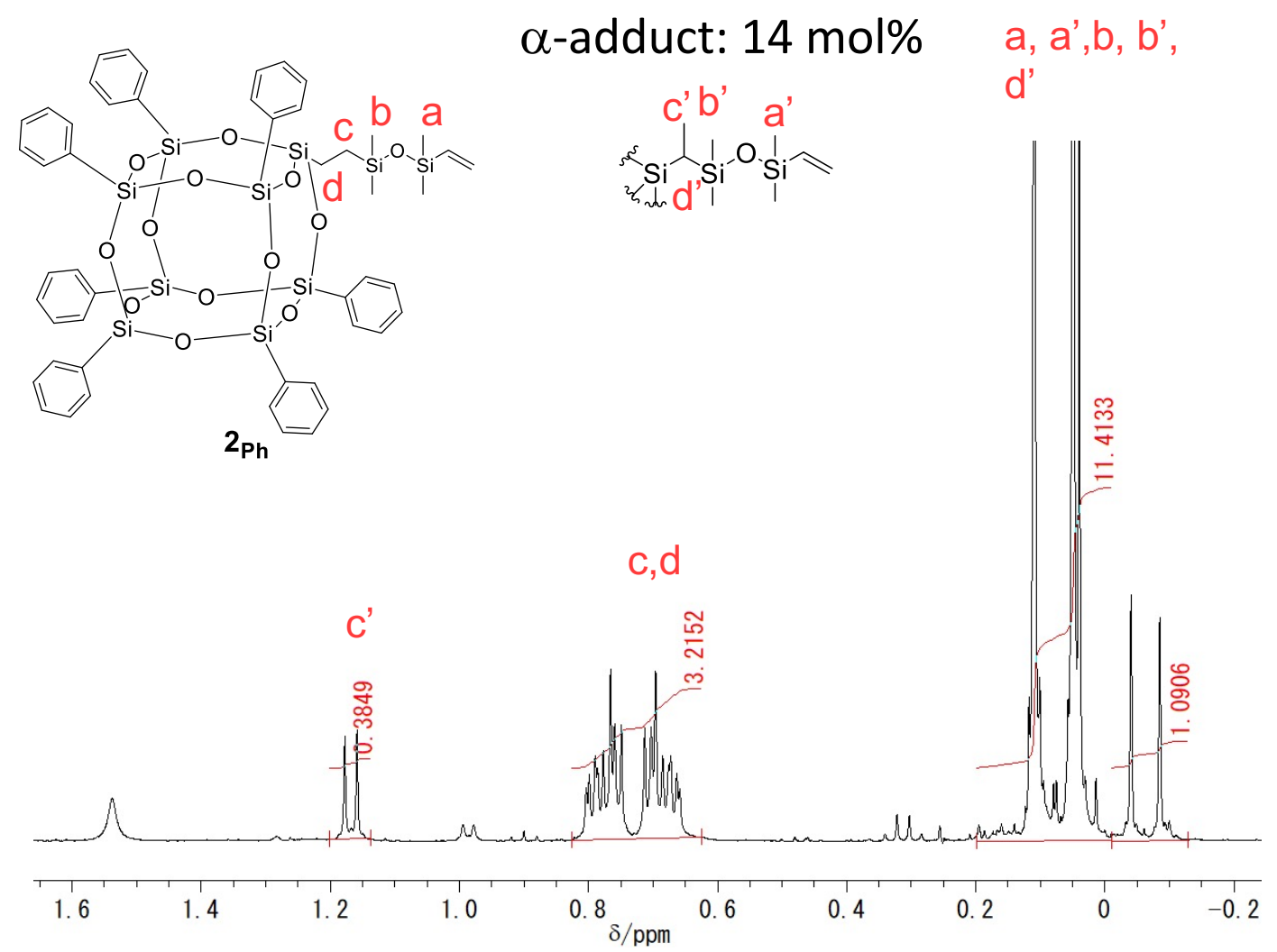

Figure S14 (a) ${ }^{1} \mathrm{H}-\mathrm{NMR}\left(400 \mathrm{MHz}\right.$ ) and (b) expanded spectra of $\mathbf{2}_{\mathbf{P h}}$ in $\mathrm{CDCl}_{3}$. 

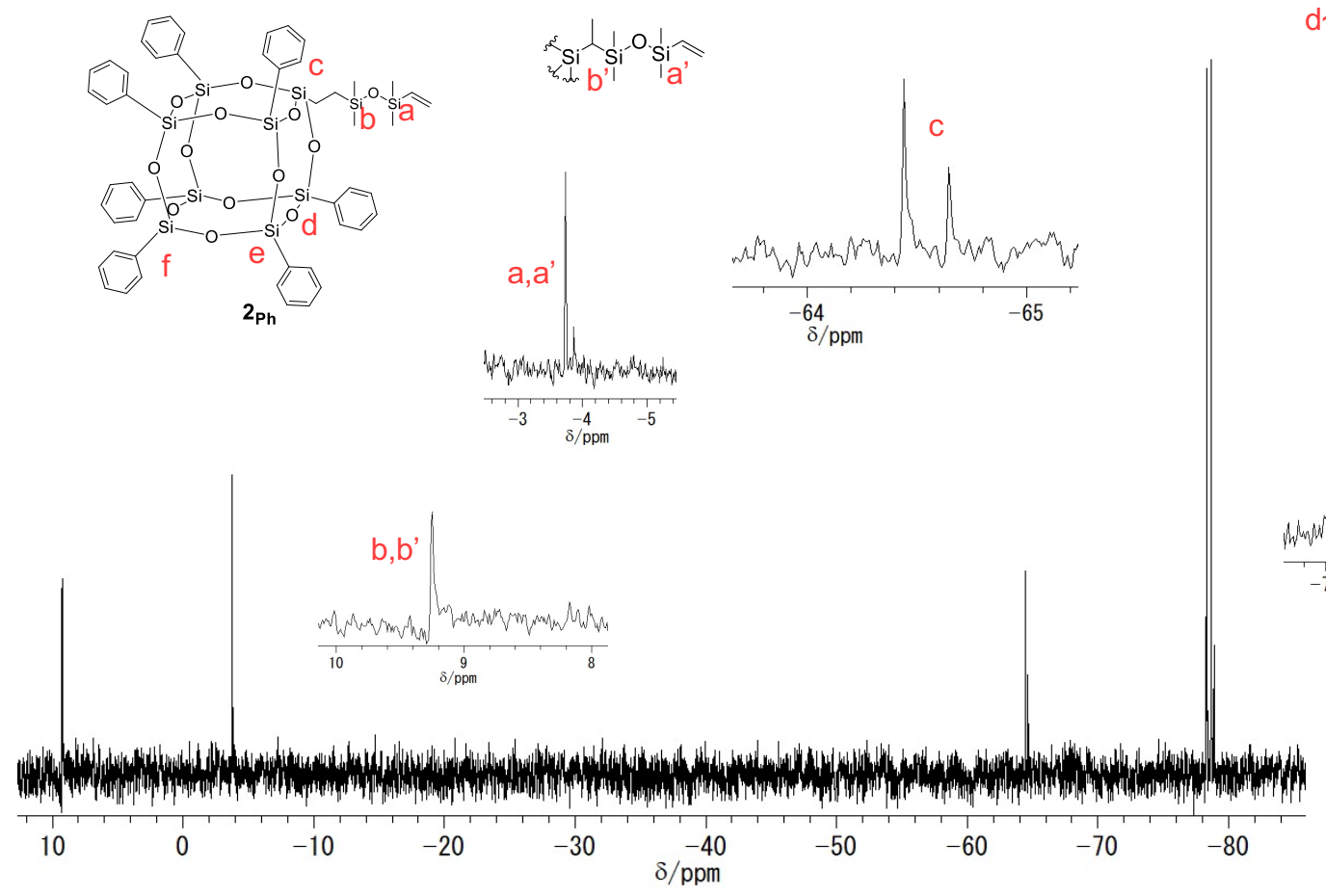

Figure S15 ${ }^{13} \mathrm{C}$-NMR $(100 \mathrm{MHz})$ spectrum of $\mathbf{2}_{\mathbf{P h}}$ in $\mathrm{CDCl}_{3}$.

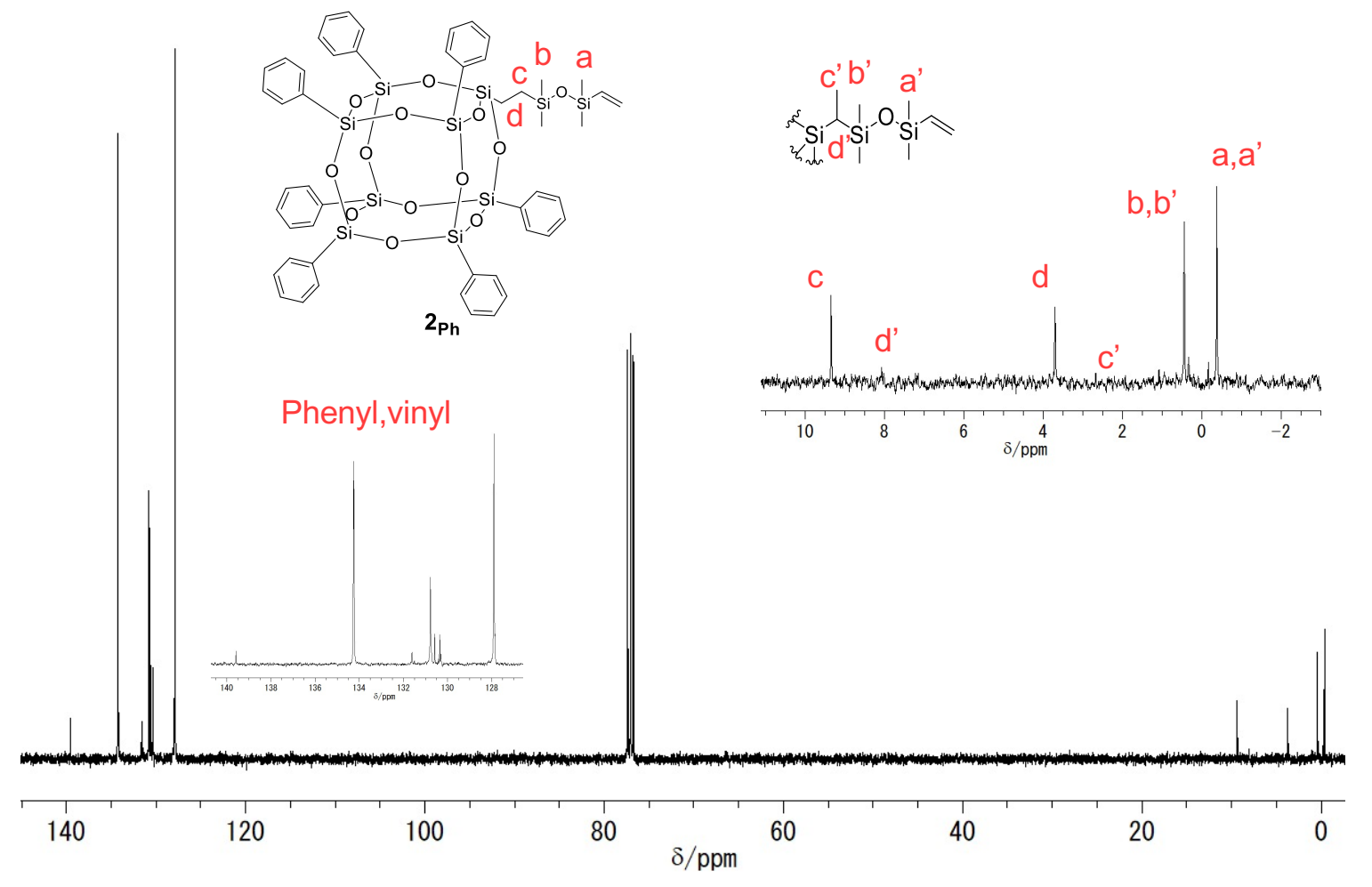

Figure $\mathbf{S 1 6}{ }^{29} \mathrm{Si}-\mathrm{NMR}(80 \mathrm{MHz})$ spectrum of $\mathbf{2}_{\mathbf{P h}}$ in $\mathrm{CDCl}_{3}$. 

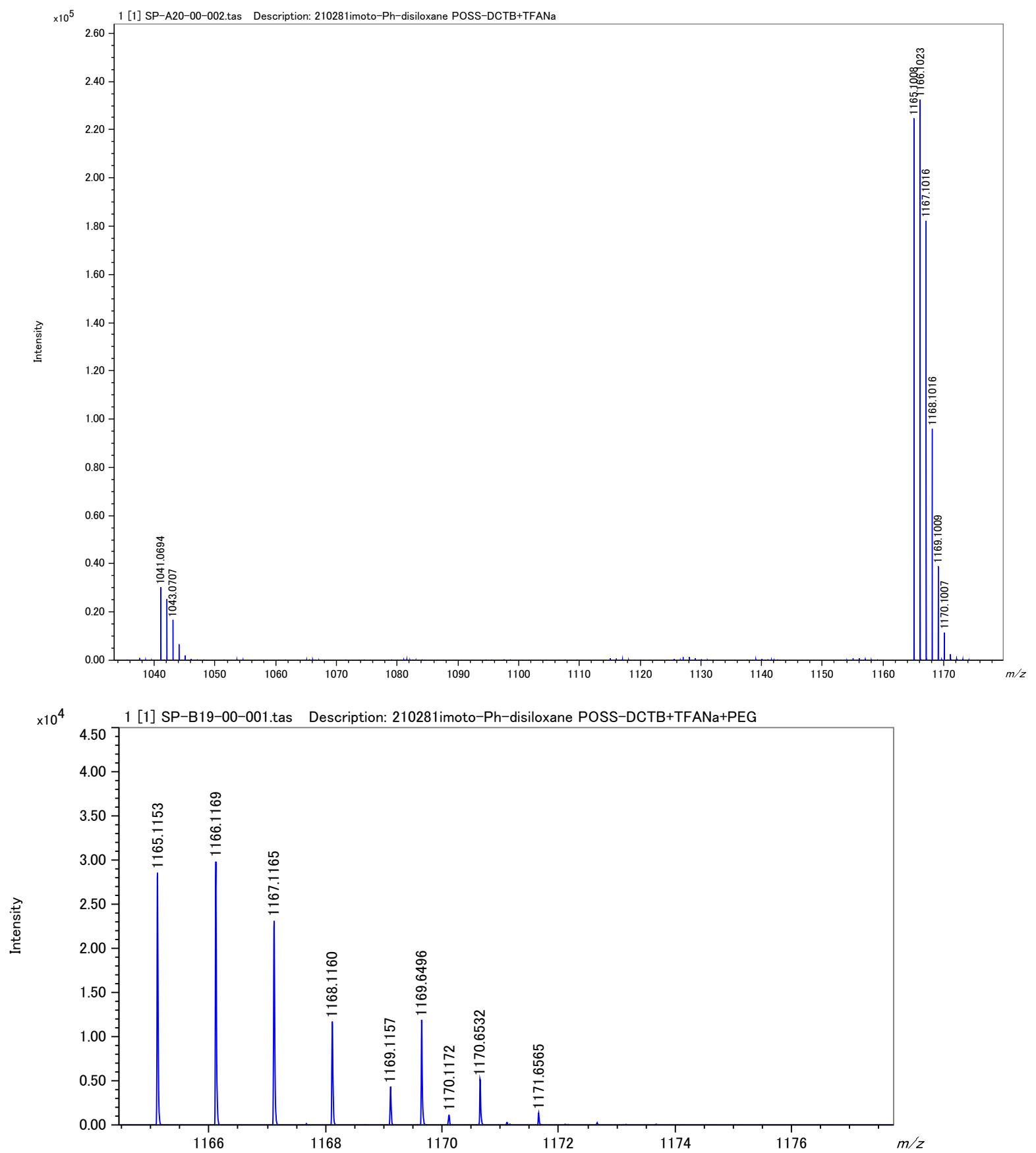

Figure S17 MALDI TOF MS spectrum of $\mathbf{2}_{\mathbf{P h}}$. Matrix: DCTB (20 $\mathrm{mg} / \mathrm{mL}$ in $\left.\mathrm{CHCl}_{3}\right)$, cationizing agents: sodium trifluoroacetate $(1 \mathrm{mg} / \mathrm{mL}$ in THF). (a) Full spectrum and (b) expanded view. 
(a)
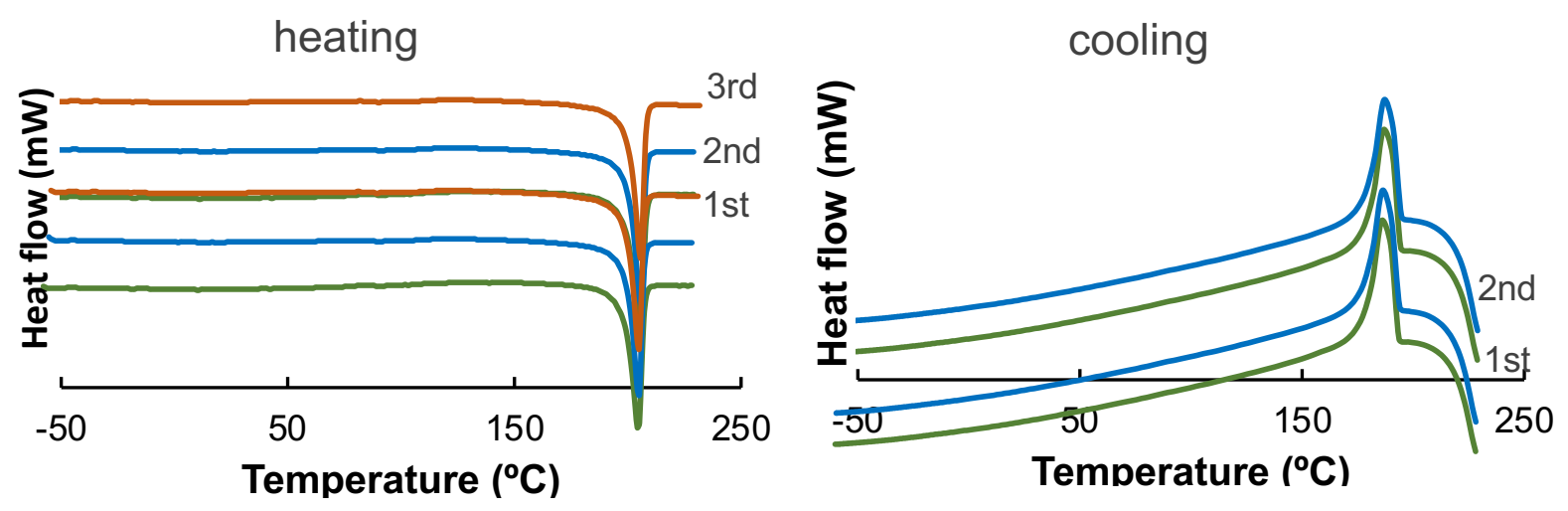

(b)
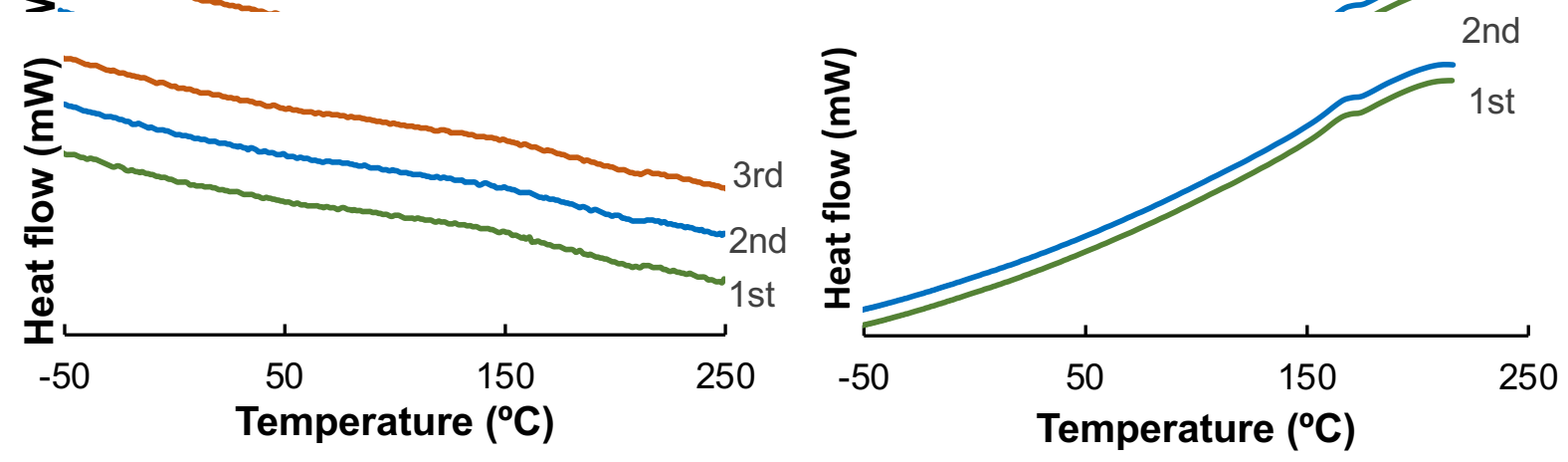

(c)
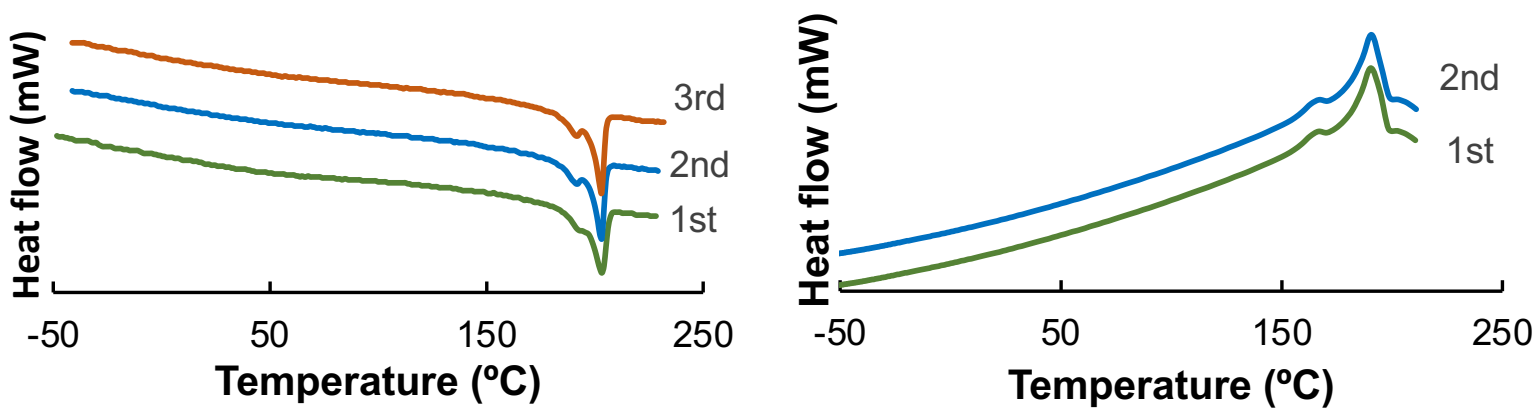

Figure S18 First, second and third scans in DSC analysis of $\mathbf{3}_{\mathrm{iBu}}$-iBu from $-60{ }^{\circ} \mathrm{C}$ to $230{ }^{\circ} \mathrm{C}$ (a), $\mathbf{3}_{\mathbf{P h}-\mathbf{P h}}-60{ }^{\circ} \mathrm{C}$ to $370{ }^{\circ} \mathrm{C}(\mathrm{b})$, and equimolar mixture of $\mathbf{3}_{\mathbf{i B u}-\mathbf{B B u}}$ and $\mathbf{3}_{\mathbf{P h}-\mathbf{P h}}-60{ }^{\circ} \mathrm{C}$ to $230{ }^{\circ} \mathrm{C}$ (c) at heating rate of $10{ }^{\circ} \mathrm{C} / \mathrm{min}$ and cooling rate of $10{ }^{\circ} \mathrm{C} / \mathrm{min}$ in $\mathrm{N}_{2}$ flow. 


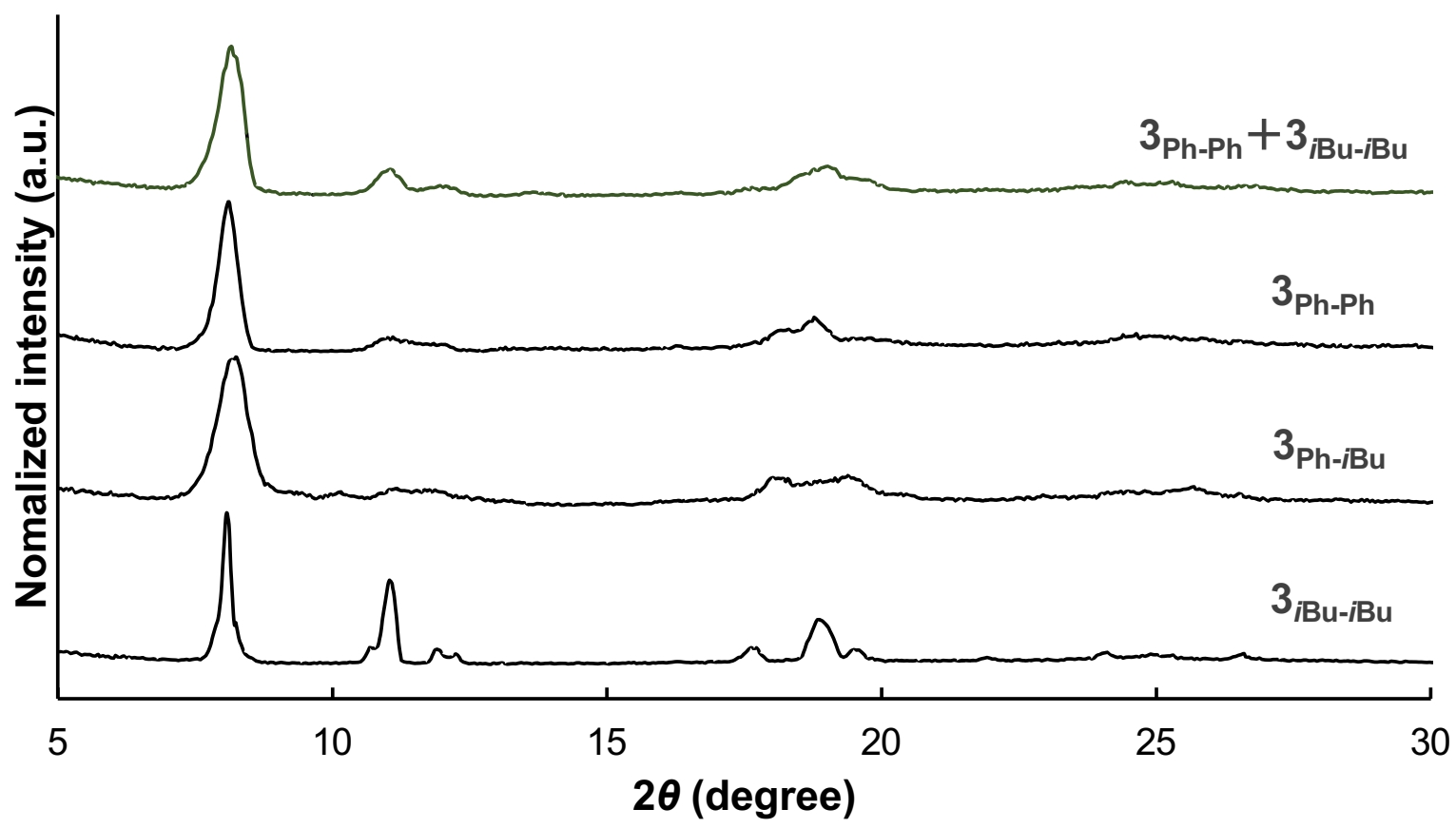

Figure S19 XRD traces of $\mathbf{3}_{\mathrm{iBu}-\mathrm{iBu}}, \mathbf{3}_{\mathbf{P h}-\mathbf{P h}}, \mathbf{3}_{\mathbf{P h}-\mathrm{iBu}}$, and equimolar mixture of $\mathbf{3}_{\mathrm{iBu}-\mathrm{iBu}}$ and $\mathbf{3}_{\mathbf{P h}-\mathbf{P h}}$ at room temperature. 